\title{
ÁREAS LIVRES PÚBLICAS DA MICRORREGIÃO 07 - USO E OCUPAÇÃO DO SOLO URBANO EM PRESIDENTE PRUDENTE - SP
}

\author{
Caroline Salvatori Machado', Jéssica Akemi Hayashi', Thais Cabrera Leite ${ }^{1}$, Mayara Pissutti Albano', \\ Fabrícia Moraes Fernandes Borges ${ }^{1}$, Marcos Boin², Sibila Corral de Arêa Leão Honda \\ ${ }^{1}$ Universidade do Oeste Paulista - UNOESTE, Faculdade de Engenharias e Arquitetura e Urbanismo, \\ Presidente Prudente, SP. ${ }^{2}$ Universidade Federal da Grande Dourados - UFGD, Dourados - MS.
}

\section{RESUMO}

A presente pesquisa tem como objetivo levantar e mapear as áreas livres públicas da Microrregião Administrativa 07 na cidade de Presidente Prudente - SP, bem como identificar os usos atuais de tais áreas e verificar se estão em conformidade com a legislação pertinente. As áreas livres púbicas são de vital importância para as cidades contemporâneas, pois agregam valores ambientais, sanitários, estéticos, entre outros. Também colaboram para a qualidade de vida da população residente nas cidades. A necessidade de se ter um banco de terras destinadas para esse fim foi instituída à partir de 1979, através da Lei Federal n.6.766, que deu ao município o poder de regulamentar o uso e a ocupação do solo urbano partindo de exigências mínimas. Pesquisas bibliográficas, documentais e levantamentos físicos territoriais são os procedimentos metodológicos que deverão ser cumpridos para o desenvolvimento da pesquisa.

Palavras-chave: Áreas livres; áreas públicas, urbanização, microrregião 07, Presidente Prudente.

\section{PUBLIC OPEN SPACES OF MICROREGION 07 - A STUDY ABOUT USE AND OCCUPANCY OF URBAN LAND IN PRESIDENTE PRUDENTE - SP.}

\begin{abstract}
The present research aims to survey and map the public open space of Microregion 07 on Presidente Prudente - SP, as well identifying the current use of such areas and verifying if they are in accordance with the current law. The public open spaces are important for contemporary cities because they attach environmental, aesthetic values, etc. Also collaborate to the quality life of people living in the cities. The necessity of having a land bank intended for this purpose was established since 1979, through Federal Law n.6.766, which gave to the city power of regulate the use and occupancy of urban land from minimum requirements. Bibliographical, documental researches and physic-territorial survey are the methodology procedure that must be fulfilled in this development research.
\end{abstract}

Keywords: Open spaces, public areas, urbanization, microregion 07, Presidente Prudente. 


\section{INTRODUÇÃO E JUSTIFICATIVA}

A composição do espaço urbano se dá através de espaços edificados, que são ocupados predominantemente por edificações, e espaços livres, ambos, com interferência humana, institucionalizadas ou não (SÁ CARNEIRO e MESQUITA; 2000).

Espaço livre é um conceito de difícil definição, pois podem ser encontradas divergências entre diversos autores. Nucci (2001) afirma que o termo é muito abrangente, pois os espaços livres fazem parte de um grande grupo paisagístico urbano, que está sujeito a subdivisões em função de seu uso e da escala de análise, assim, ele agrega todos os outros conceitos similares, tais como: espaços abertos, áreas livres, áreas verdes, sistemas de áreas de lazer, cobertura vegetal entre outros, que também são muito utilizados para definir esses espaços.

A falta de planejamento urbano e o crescimento desordenado das cidades brasileiras embaraçam a implantação de áreas urbanas para formar um sistema de espaços livres públicos adequados, que atenda de maneira ampla e coerente toda a cidade (MENNHE e COELHO, 1999).

A Lei Federal n.6.766 promulgada em 1979, atribuiu ao município o controle sobre o parcelamento, uso e ocupação do solo urbano, e estabeleceu a obrigatoriedade do desenvolvimento de uma reserva para a implantação do sistema de áreas verdes, áreas institucionais, destinadas à implantação de equipamentos públicos comunitários, e sistema viário na tentativa de fornecer às cidades brasileiras uma revisão de suas formas de ocupação e distribuição dos espaços livres.

O Estatuto da Cidade, Lei complementar n.10.257/2001, que regulamenta o capítulo de política urbana da Constituição, corrobora que:

A política urbana tem por objetivo ordenar o pleno desenvolvimento das funções sociais da cidade e da propriedade urbana, mediante [...] : Voferta de equipamentos urbanos e comunitários, transporte e serviços públicos adequados aos interesses e necessidades da população e às características locais (art. 2ㅇ..).

Apoiado neste contexto, busca-se, por meio do presente artigo, aprofundar os conhecimentos nos assuntos relacionados as áreas livres públicas na cidade de Presidente Prudente, tendo a Microrregião Administrativa 07 como recorte, para que se possa verificar, quais que sofreram alteração de uso, mapeando-as e identificando seus atuais usos e ocupação, e compará-los com as disposições legais. Destaca-se que a cidade de Presidente Prudente foi dividida em 18 Microrregiões Administrativas pela Prefeitura Municipal, não oficialmente, para possibilitar e facilitar os levantamentos da própria Prefeitura e do Ministério Público, relativas a falta de áreas públicas aprovadas legalmente e com usos alterados, conforme consta no Inquérito Civil - IC No MP : 14.0720.0000322/2.011-1.

O objetivo geral do trabalho é analisar áreas definidas como áreas livres públicas e institucionais em loteamentos que compõem a 7ạ Microrregião Administrativa de Presidente Prudente, verificando sua real utilização na atualidade, e conformidade com as leis que regulamentam o uso e ocupação do solo, tendo como referência os processos do Ministério Público Estadual.

\section{METODOLOGIA}

Realizou- se um levantamento bibliográfico a fim de identificar as principais produções sobre áreas livres públicas e áreas institucionais, bem como outros assuntos relacionados ao tema.

$\mathrm{Na}$ sequência, foi realizada uma pesquisa documental, para que fosse identificadas políticas, ações voltadas às áreas livres públicas e áreas institucionais, legislação municipal, estadual e federal relacionadas ao parcelamento, uso e ocupação do solo urbano; posteriormente, 
foram feitos levantamentos físico territoriais das áreas livres públicas e das áreas institucionais, assim como mapeamentos de aspectos como: equipamentos e serviços, a localização e a conformidade dos usos aos quais foram destinadas. Os mapeamentos foram realizados por meio do software Spring.

\section{DISCUSSÃO}

O espaço urbano pode ser definido, com relação a seus aspectos físicos, como uma mescla de espaços edificados, ou seja, áreas ocupadas predominantemente por edificações, e de espaços livres, que são resultados das ações humanas (SÁ CARNEIRO e MESQUITA; 2000).

O espaço público é o lugar de representação e de expressão coletiva da sociedade pela filosofia política, é o lugar, por excelência, da socialização (BORJE, 2003). O espaço público urbano é formado por áreas de lazer, áreas verdes e pelo sistema viário.

Os espaços livres públicos podem ter caráter funcional como a circulação urbana, sociais e culturais através do convívio público, como ambientais na conservação e requalificação ambiental, sendo elementos fundamentais na estrutura das cidades, não devendo ser negligenciados. Para Leite (2011) os principais atributos de um espaço público são aqueles relacionados com a vida pública, com urbanidade, possibilitando diversidade de situações e pessoas.

A partir da década de 1950, o processo de urbanização brasileiro sofreu intensificação, gerando enorme movimento de construção da cidade legal e ilegal. No entanto, tal crescimento gerou problemas no tocante as necessidades urbanas, como moradia, trabalho, abastecimento, saúde, energia e lazer (MARICATO, 2013).

Visando a melhoria e o controle do Parcelamento do Solo urbano, é outorgada a Lei Federal 6.766/79. O parcelamento do solo tem como objetivo organizar o crescimento das cidades, entretanto não se deve considerar apenas a atividade econômica gerada a partir dos lotes urbanos, mas também a estética, sanidade, segurança e educação. Por fim essas áreas devem apresentar boas condições à população, colaborando com a qualidade de vida urbana.

Segundo esta Lei, as áreas destinadas a espaços livres e equipamentos urbanos devem ser registradas em Cartório (art. 20) e pertencem ao Município (art. 22). A referida Lei não apresenta exceções à hipótese de reserva de áreas destinadas à construção de equipamentos urbanos e comunitários e foi enfática ao subordinar a aprovação da localização destas, bem como da descrição de percentuais da área total da gleba a ser loteada, pelo poder público municipal.

A cidade de Presidente Prudente -SP, foi, ao longo de sua história, contemplada com três Planos Diretores, 1968, 1996 e em 2008, quando sofreu última revisão, que está em vigor até os dias de hoje. A referida lei, dispõe sobre o parcelamento do solo urbano, em seu artigo 12, estabelece que os loteamentos deverão atender, pelo menos, os seguintes requisitos:

"I - as áreas públicas serão proporcionais à densidade de ocupação prevista para a gleba;

II - as áreas públicas, depois de descontadas as áreas de preservação, não serão inferiores a 35\% (trinta e cinco por cento) da gleba total;

III - as áreas públicas compor-se-ão, no mínimo de:

a) áreas institucionais: $5 \%$ (cinco por cento) a 10\% (dez por cento) da área loteável, a critério do órgão responsável pelo Planejamento do município, sendo isolada pelo Sistema Viário;

b) áreas de lazer: $10 \%$ (dez por cento) a 15\% (quinze por cento) da área loteável;

c) sistema viário ou arruamento; mínimo $20 \%$ (vinte por cento) da área loteável;

d) áreas de preservação, quando for o caso; 
e) áreas "NON AEDIFICANDI", quando for o caso"

A Microrregião Administrativa 07, objeto de estudo da presente pesquisa, é composta pelos seguintes bairros: Central Park Residence, Central Park II, Jardim Aquinópolis, Jardim Caiçara, Jardim Cambuí, Jardim Campo Belo, Jardim Cinquentenário, Jardim Colina, Jardim das Rosas, Jardim Esplanada, Jardim Icaraí, João Paulo II, Jardim Marupiara, Morumbi, Jardim Paris, Jardim Petrópolis, Jardim São Luiz, Parque Residencial Araki, Parque das Cerejeiras, Residencial Pacaembu, Residencial Vivenda e Vila Mathilde Vieira.

Através das pesquisas realizadas constatou-se irregularidades nos bairros que compõem a Microrregião 07, os resultados serão apresentados a seguir.

\section{RESULTADOS}

Tendo base nos estudos realizados a partir dos documentos acima citados, do levantamento físico e mapeamento vetorizado, foram constatadas pequenas irregularidades referente a microrregião em analise (Figura 1).
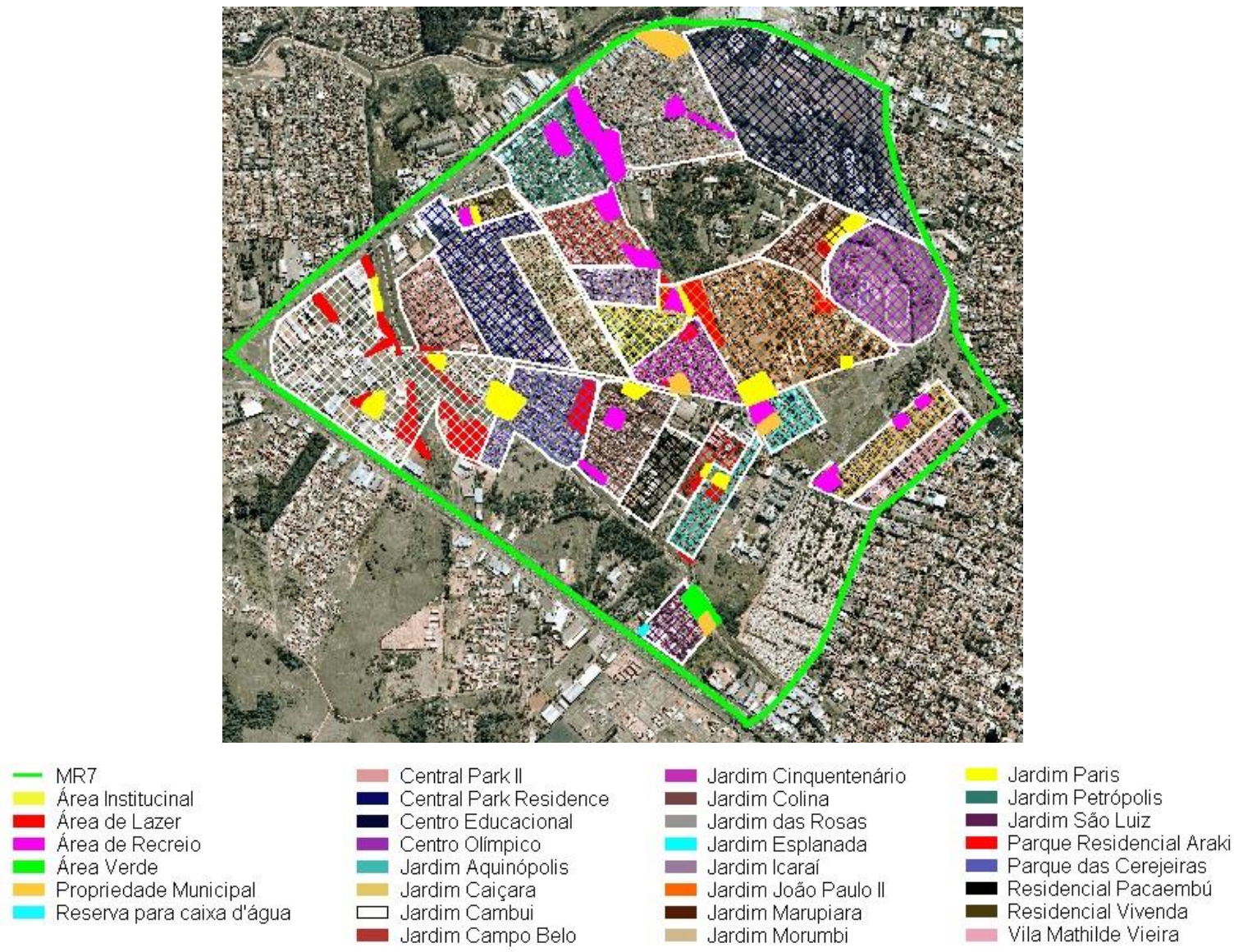

Figura 01. Microrregião 07

Fonte: Autores, 2016.

Dos dezessete bairros pertencentes à área em estudo, $47 \%$ deles possuem algum tipo de irregularidade em relação aos espaços considerados de uso publico, não seguindo a aplicação devida. Os gráficos a baixo representam a totalidade das áreas relacionadas. 


\section{Áreas institucionais}

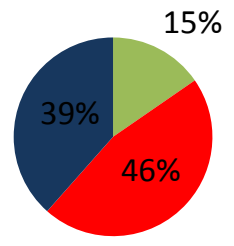

- USO DEVIDO

- USO INDEVIDO

- SEM UTILIZAÇÃO

\section{Áreas de lazer/recreio}

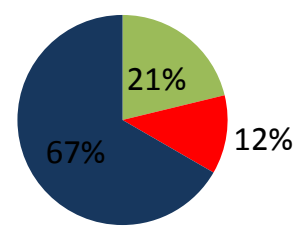

Gráfico 01. Relação dos usos do solo urbano na Microrregião 07 Fonte: autores, 2016

Os bairros que apresentam desvio de função das áreas institucionais são; o Residencial Vivenda, Jardim Petrópolis, Jardim Paris, Jardim Marupiara, Jardim João Paulo II e Jardim Aquinópolis.

Tabela 01. Relação dos desvios de função das áreas institucionais da Microrregião 07.

\begin{tabular}{|l|l|c|l|}
\hline IDENTIFICAÇÃO & \multicolumn{1}{|c|}{ BAIRRO } & ÁREA $\left.\mathbf{~ m}^{\mathbf{3}}\right)$ & \multicolumn{1}{c|}{ USO ATUAL } \\
\hline Área 1 & Residencial Vivenda & $1.217,15$ & Idottur- Agência de turismo \\
\hline Área 2 & Jardim Petropolis & $7.140,00$ & Justiça Federal \\
\hline Área 3 & Jardim Paris & $1.665,79$ & Centro Espirita \\
\hline Área 4 & Jardim Marupiara & $2.514,24$ & Ordem dos Advogados do Brasil (OAB) \\
\hline Área 5 & Jardim João Paulo II & $7.434,00$ & Escola particular Multiplos \\
\hline Área 6 & Jardiim Aquinópolis & $2.224,60$ & Associação paulista dos cirurgiões dentista \\
\hline
\end{tabular}
Fonte: autores, 2016

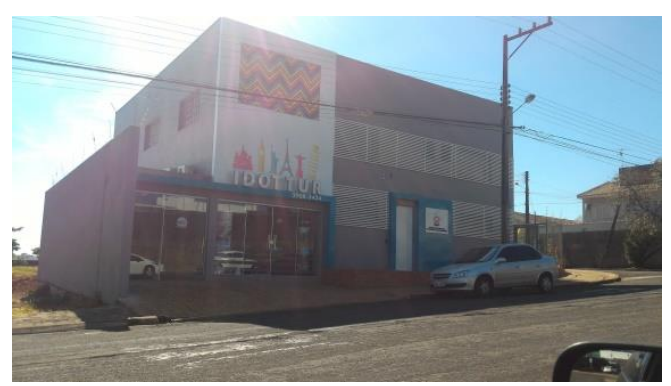

Figura 1. Idottur, agência de turismo Fonte: autores, 2016

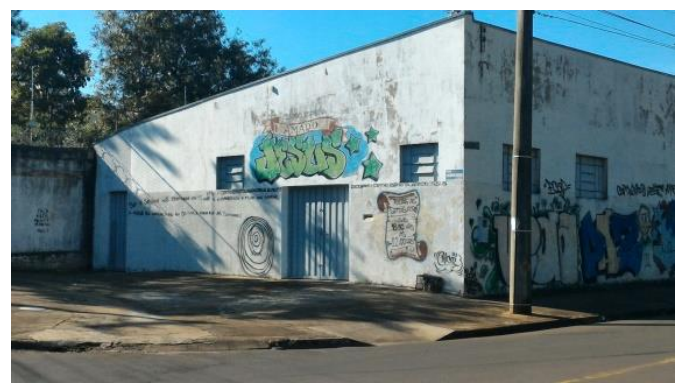

Figura 3. Centrol espirita Fonte: autores, 2016

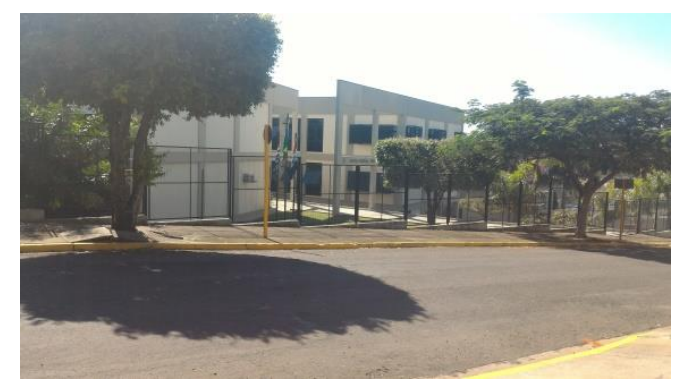

Figura2. Justiça Federal

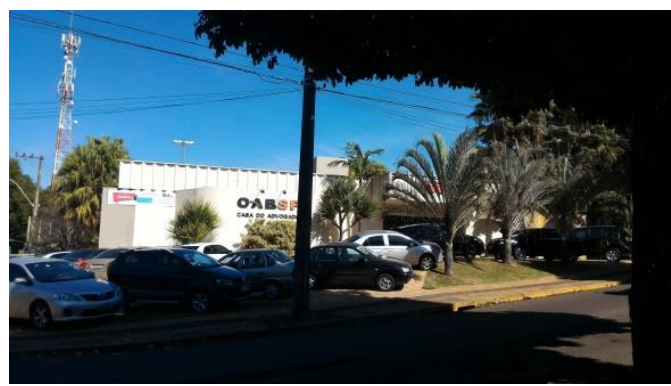

Figura 4. Ordem dos advogados do Brasil- $O A B$ 

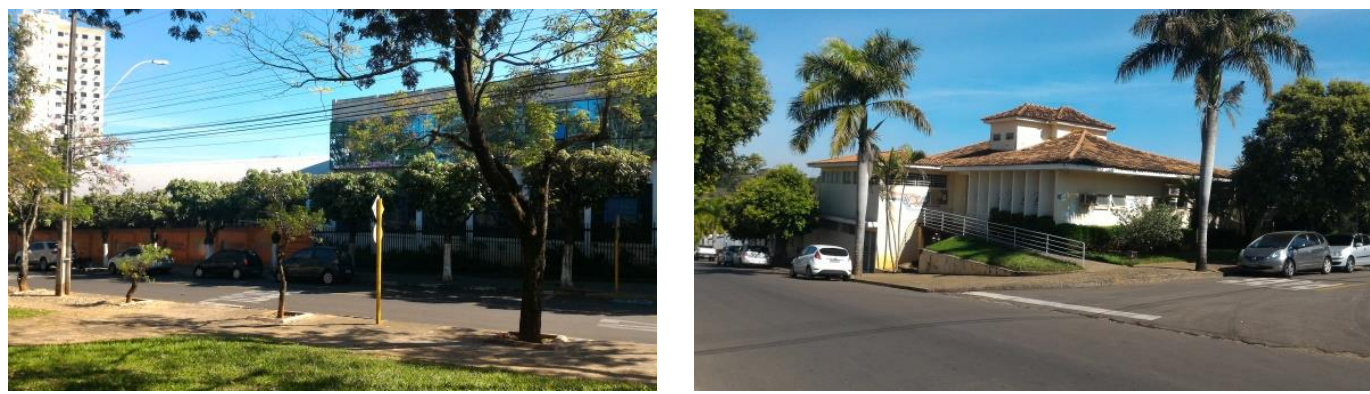

Figura 5. Colégico Mulpitlos Fonte: autores, 2016

Figura 6. Associação paulista dos cirurgiões dentista

Já tendo em vista as áreas reservadas para lazer ou recreio de cada bairro que abrange a MR7, também foi feito um levantamento físico que nos proporcionou os seguintes dados; os bairros Jardim Aquinópolis e Jardim Caiçara, onde o uso do solo se diferencia do destinado. $O$ restante dos bairros que completam a sétima microrregião estão de acordo com os usos atribuídos, exceto alguns lotes que possuem está função pública ainda não há nenhum tipo de utilização.

Tabela 2. Relação dos desvios de função das áreas de lazer da Microrregião 07.

Fonte: autores, 2016

\begin{tabular}{|c|c|c|}
\hline BAIRRO & ÁREA $\left(\mathrm{m}^{2}\right)$ & USO ATUAL \\
\hline \multirow[t]{3}{*}{ Jradim Caiçara } & 4.009 & E.E Maria Luiza Bastos \\
\hline & $1.710,80$ & Residencial \\
\hline & $1.710,80$ & Residencial \\
\hline Jardim Aquinópolis & $2.611,70$ & $\begin{array}{l}\text { Associação paulista dos } \\
\text { cirurgiões dentistas }\end{array}$ \\
\hline
\end{tabular}

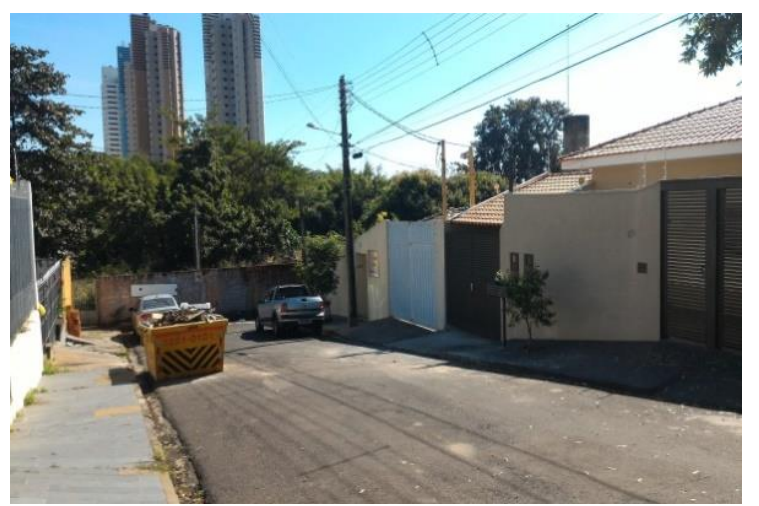

Figura 7. Residenciais- Jardim Caiçara

Fonte: autores, 2016
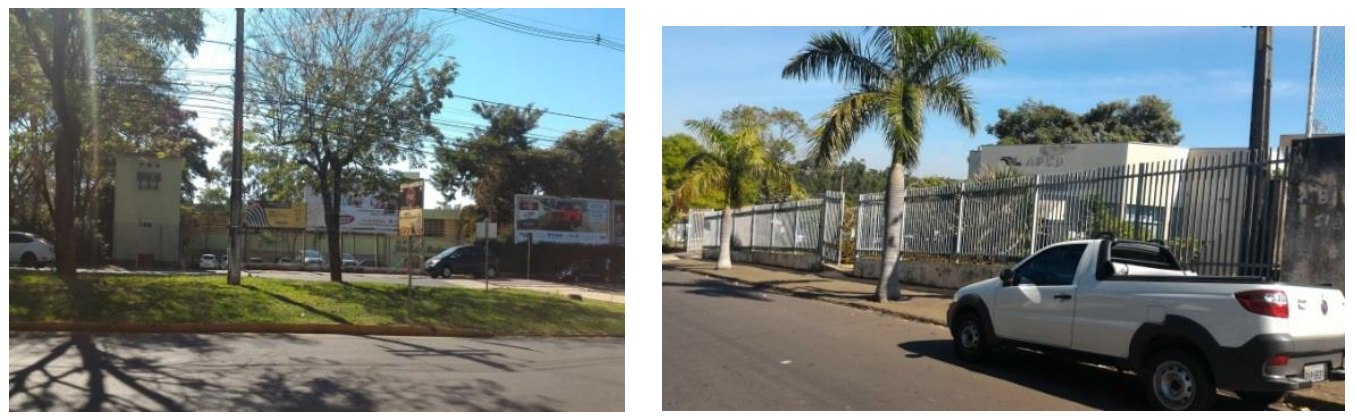

Figura 8 - E.E Maria Luiza Bastos

Figura 9 - Associação paulista dos cirurgiões dentista

Fonte: autores, 2016 


\section{CONSDERAÇÕES FINAIS}

Através das análises dos referenciais teóricos, concluiu-se que as áreas verdes e institucionais possuem uma grande importância no contexto das cidades. Entretanto, em Presidente Prudente - SP, com destaque para Microrregião 07, não se tem dado a devida importância, visto que muitas se encontram em desconformidade com a lei.

É necessário que se tenha um cuidado especial com tais áreas que sofreram desvio de função para que a população residente nesse espaço não seja prejudicada de alguma forma, visto que essa falta que pode comprometer a qualidade de vida local.

\section{REFERÊNCIAS}

BRASIL. Lei n.6.766, de 19 de dezembro de 1979. Dispõe sobre o parcelamento do solo urbano e dá outras providências.

BRASIL. Lei n. 10.257, de 10 de julho de 2001. Regulamenta os arts. 182 e 183 da Constituição Federal, estabelece diretrizes gerais da política urbana e dá outras providências. (Estatuto da Cidade).

BORJE, J. La ciudad conquistada. Madrid: Alianza Editorail, 2003.

LEITE, M.A.F.P. Um sistema de espaços livres para São Paulo. Estud. av., São Paulo, v. 25, n. 71, 2011

MARICATO, Ermínia. Brasil cidades: alternativas para a crise urbana. Petrópolis, RJ: Vozes, 2001.

MENNHE, M.H.; COELHO, A.M. Características do sistema de parques públicos urbanos da cidade de São Paulo. In: ENTAC, 8, 2000, Salvador. ANAIS, Salvador: ANTAC., 2000. 8 p. CD-ROM. Seção artigos.

NUCCI, J.C. Qualidade ambiental e adensamento urbano: um estudo de ecologia e planejamento da paisagem aplicado ao distrito de Santa Cecília (MSP). 2a ed. Curitiba: O Autor, 2008. 150 p.

PRESIDENTE PRUDENTE. Prefeitura Municipal. Plano Diretor do Município.Lei complementar n. 151/2008.PresidentePrudente, 2008.

SÁ CARNEIRO, A.R.; MESQUITA, L.B. Espaços Livres do Recife. Recife: Prefeitura da Cidade do Recife. Universidade Federal de Pernambuco, 2000. 